\title{
Erratum to: Radiofrequency Ablation of Barrett's Esophagus: Let's Not Get Ahead of Ourselves
}

\author{
Gary W. Falk
}

Published online: 24 July 2010

(C) Springer Science+Business Media, LLC 2010

Erratum to: Dig Dis Sci (2010) 55:1811-1814

DOI 10.1007/s10620-010-1292-4

The final sentence in the paragraph "Magnitude of Treatment Effect" on page 1813 should read as follows:
If we hypothesize that RFA decreases cancer risk by $50 \%$ from 0.6 to $0.3 \%$ per year for an absolute risk reduction of $0.3 \%$ annually, then the number needed to treat to prevent one cancer is $1 /$ absolute risk reduction $(1 / 0.003)$ or 333 patients.

The online version of the original article can be found under doi:10.1007/s10620-010-1292-4.

G. W. Falk $(\bowtie)$

Hospital of the University of Pennsylvania, Division of Gastroenterology, University of Pennsylvania School of Medicine, 3 Ravdin, 3400 Spruce Street, Philadelphia, PA 19104, USA

e-mail: gary.falk@uphs.upenn.edu 